\title{
MK-801 protects conditioned responses from extinction in the rabbit nictitating membrane preparation
}

\author{
E. JAMES KEHOE, MICHAELA MACRAE, and CATHERINE L. HUTCHINSON \\ University of New South Wales, Sydney, New South Wales, Australia
}

\begin{abstract}
MK-801 is a noncompetitive antagonist to $N$-methyl-D-aspartate (NMDA) receptors. MK-801 was given $(0.05$ or $0.10 \mathrm{mg} / \mathrm{kg}$ i.v.) to rabbits during extinction of a well-established conditioned response (CR) in the nictitating membrane preparation. The drug administration produced an immediate deficit in CR performance during extinction. However, when MK-801 administration was suspended, CRs reappeared immediately and showed no evidence of the previous extinction treatment. In addition, we confirmed previous findings that MK-801 impairs both the acquisition and the expression of CRs during CS-US training. A reduction in CS processing caused by MK-801 is the most parsimonious explanation of the data. There are also two-factor alternatives, which contend that MK-801 directly hinders associative formation and either directly blocks CR output or produces a state-dependent generalization decrement.
\end{abstract}

MK-801 may impair the processes of synaptic plasticity that underlie associative learning. Specifically, MK-801 is a noncompetitive antagonist to $N$-methyl-D-aspartate (NMDA) receptors (Kemp, Foster, \& Wong, 1987), which are thought to act as "conjunction devices" that increase synaptic efficacy where pre- and postsynaptic inputs converge (Collingridge, Kehl, \& McLennan, 1983; Cotman \& Iversen, 1987; Lynch et al., 1990; Morris, Davis, \& Butcher, 1990). It follows that antagonists of NMDA receptors, such as MK-801, should impair associative learning. Moreover, since the role of NMDA receptors in fast excitatory transmission appears minimal (but see Miserendino \& Davis, 1993), MK-801 would not be expected to impair the expression of learned responses. Indeed, the NMDA antagonists AP5 and MK-801 have been shown to block the acquisition but not the expression of both long-term potentiation (Gilbert \& Mack, 1990; Muller, Joly, \& Lynch, 1988) and fear-based learning in rats (Cox \& Westbrook, 1994; Miserendino, Sananes, Melia, \& Davis, 1990). Conversely, antagonists for non-NMDA receptors block the expression but not the acquisition of conditioned fear in rats (Kim, Campeau, Falls, \& Davis, 1993).

Although MK-801 impairs learning in some response systems, MK-801's effects are not confined to associative learning in all response systems (e.g., Keith \& Rudy, 1990). Research using the rabbit's nictitating membrane (NM) response has revealed that MK-801 strongly hinders both the acquisition and the expression of conditioned responses (CRs). There have been five key findings in this regard:

Preparation of this manuscript was supported by Australian Research Council Grant AC9231222. Correspondence should be sent to E. J. Kehoe, School of Psychology, University of New South Wales, Sydney, NSW 2052, Australia (e-mail: j.kehoe@unsw.edu.au).
1. $M K-801$ profoundly impairs $C R$ acquisition. A dose of $0.10-\mathrm{mg} / \mathrm{kg}$ MK- 801 has entirely precluded CR acquisition in about half of all rabbits and reduced the rate of $\mathrm{CR}$ acquisition in the rest. This degree of impairment has been observed when the drug was administered intravenously or subcutaneously, when the conditioned stimulus (CS) was either tone or light, and when the unconditioned stimulus (US) was either electrotactile stimulation or a corneal air puff (Cox, Guthrie, Macrae, \& Kehoe, 1994; Robinson, 1993). A dose of 0.05-mg/kg MK-801 has produced less impairment (Robinson, 1993).

2. Impairment in the $C R$ remains when $M K-801$ is suspended. When saline was substituted for MK-801, there was no evidence of an immediate increase in the level of responding to the CS, nor were there any savings during subsequent CS-US training (Cox et al., 1994; Robinson, 1993).

3. MK-801 impairs the expression of established CRs. In control rabbits that had received CS-US training under saline, MK-801 immediately and dramatically reduced responding. Specifically, Robinson, Port, and Stillwell (1993) found that a $0.10-\mathrm{mg} / \mathrm{kg}$ dose reduced CR likelihood by approximately $30 \%$. Similarly, Cox et al. (1994) observed reductions of $40 \%-50 \%$ using a $0.10-\mathrm{mg} / \mathrm{kg}$ dose.

4. When multiple CSs are combined, established CRs resist the otherwise deleterious effects of $M K-801$. Cox et al. (1994) trained control rabbits with a separate tone CS and light CS. When MK-801 was administered and the two CSs were combined, the mean CR likelihood dropped only $24 \%$. This drop was significant but was much smaller than the deficits seen on separate tone and light tests. Thus, with sufficient stimulation, enough of the CSs were processed to enable expression of the CR.

5. Established CRs reappear when $M K-801$ is suspended. The day following administration of MK-801, the level of responding in control rabbits immediately returned 
to the levels seen before administration of MK-801 (Cox et al., 1994).

The deleterious effects of MK- 801 in the NM preparation appear to be relatively specific to CRs and not caused by general deficits in the sensory or motor systems relevant to the NM system. MK-801 does not affect sensory processing of an electrotactile US, for example, by producing anesthesia, nor does MK-801 affect performance of the unconditioned response (UR), for example, by producing general motor impairments. Specifically, on US-alone and CS-US trials, MK-801 has failed to produce any discernible reduction in the magnitude of the UR, even for weak intensities of the electrotactile US. However, for an air-puff US, Robinson and his associates have observed that MK801 does reduce the UR in the NM preparation across the full range of US intensities (Robinson, 1993; Robinson et al., 1993). This difference between the USs suggests that sensory processing of the corneal air puff may be more susceptible than the electrotactile US to disruption by MK-801.

It is perhaps not surprising that the pattern of findings obtained with the NM preparation diverges from those obtained in fear-based learning, because they rely on divergent neural pathways. Whereas the neural basis of learning in, for example, fear-potentiated startle appears to reside in the amygdala (Hitchcock \& Davis, 1986; Miserendino et al., 1990), the CR in the NM preparation relies primarily on circuits in the brain stem and cerebellum (Thompson, 1986, 1990). The conditioning pathways for the NM preparation can be divided into three segments. First, there is an input segment for CSs that projects from sensory nuclei into the pontine nuclei and, hence, through mossy fibers to the cerebellar cortex (lobule HVI) and deep nuclei (lateral anterior interpositus). Second, there is a separate input segment for the US that consists of somatosensory projections to the dorsal inferior olive and its climbing fiber projections to the cerebellar cortex (HVI) and interpositus nucleus. Third, there is an output segment for the CR that originates in the interpositus nucleus and descends through the red nucleus and ultimately to motor neurons of the accessory abducens (e.g., Chapman, Steinmetz, \& Thompson, 1988; Rosenfield, Davydaitis, \& Moore, 1985). There is a separate circuit for the unconditioned reflex (US-UR), which entails a short arc running from tactile trigeminal inputs through the brain stem to motor neurons in the accessory abducens (e.g., Cegavske, Harrison, \& Torigoe, 1987).

The five key findings concerning MK-801 in the NM preparation point more toward a disruption of the CS input and less toward either the CR output or the US input. This conclusion rests particularly on the pattern of results surrounding switches in drug conditions. Removal of MK801 after training under MK-801 produced little change in the low likelihood of CRs. If the disruption had been confined to expression of learning in the CR output, then the removal of MK-801 should have resulted in an immediate rise in CR likelihood. If MK-801 had disrupted only the US input, then the introduction of MK-801 to control groups would have produced a slow extinction of CRs but not the immediate and large drop in responding actually seen.
Elimination of the CR output and US input leaves the CS input of the conditioning pathways as the final candidate for the site of MK-801's disruptive effect. Within that segment, there are two points at which MK-801 could intervene. First, MK-801 could disrupt the neural encoding of the CS prior to reaching the cerebellum (e.g., Morris et al., 1990). Second, MK-801 could disrupt the plastic changes in the cerebellum that receive the convergent inputs from the CS and US.

The available data favor the hypothesis that MK-801 disrupts CS input before it reaches the site of plasticity. When MK-801 was introduced, the control groups underwent a profound and immediate reduction in CR likelihood when tested with a single CS. Conversely, when MK801 was removed, the control groups showed an equally rapid recovery of CRs. Having eliminated the CR segment as the sole site of drug action, a disruption in CS input by MK-801 is the plausible alternative. This conclusion is bolstered by the contrast between the amount of responding to combined CSs versus single CSs. When control animals were tested with combined CSs under MK-801, there was a relatively high level of responding. Thus, established associative linkages could be activated when there was enough sensory input to surmount any disruption to CS input.

The conclusion that MK- 801 diminishes CS processing in the NM preparation is open to debate. In particular, Robinson et al. (1993) failed to find that MK-801 had an effect on latent inhibition. In latent inhibition, nonreinforced preexposure to a $C S$ retards subsequent $C R$ acquisition during CS-US training. Administration of MK-801 during CS preexposure had no discernible effect on the retardation of $\mathrm{CR}$ acquisition. Thus, to the extent that one can trust null findings, MK-801 did not appear to diminish processing of the CS when it was presented alone.

In the present study, we further tested the hypothesis that MK-801 diminishes CS processing. Specifically, we examined the effect of MK-801 during CS-alone presentations in an extinction procedure. In latent inhibition, CSalone presentations precede CS-US pairings; however, in an extinction procedure, CS-alone presentations follow CS-US pairings. If MK- 801 were to completely block CS processing, then the CR should be protected from the extinctive effect of CS-alone presentations. Consequently, when MK-801 administration is suspended, the CR should be intact.

In support of this hypothesis, the NMDA-antagonist AP5 prevents extinction of fear-potentiated startle in rats (Falls, Miserendino, \& Davis, 1992). Rats were given pairings of a light CS and a shock US. During subsequent CS-alone presentations, experimental groups were given infusions of AP5 in the amygdala. The rats were then tested without AP5 by presenting the CS plus a loud noise that elicited a startle response. In the experimental groups, the CS enhanced the amplitude of the startle response in a manner similar to that of groups that had not undergone the extinction procedure. In other control groups that had not received AP5, the ability of the CS to enhance the startle response was fully extinguished. Similarly, Cox and Westbrook (1994) have demonstrated that a systemic injection 
of MK-801 $(0.10 \mathrm{mg} / \mathrm{kg})$ prevented the extinction of conditioned hypoalgesia in rats.

\section{EXPERIMENT 1}

Experiment 1 was designed to examine the extinction of the rabbit's NM response under two different doses of MK-801. The larger dose, $0.10 \mathrm{mg} / \mathrm{kg}$, matched the dose that has consistently suppressed CR acquisition and expression in the NM preparation. The smaller dose, $0.05 \mathrm{mg} / \mathrm{kg}$, has been found previously to have a smaller effect (Robinson, 1993). Following extinction under the different drug doses, all subjects were tested without the drug to determine whether or not the CR had been protected from extinction.

\section{Method}

\section{Subjects}

In Experiment 1, the subjects were 14 male albino rabbits (Oryctolagus cuniculus). All rabbits were individually housed and had free access to food and water. The rabbits had been used previously in an experiment concerning $\mathrm{CR}$ acquisition to a tone $\mathrm{CS}$ under a changing CS-US interval (Grant, 1994).

\section{Apparatus}

The apparatus and recording procedure for the NM response were patterned after those of Coleman and Gormezano (1971), who detail modifications of those described by Gormezano (1966). In brief, each subject was restrained in a Perspex box and trained individually in one of eight conditioning chambers. In each chamber, a speaker was mounted $8 \mathrm{~cm}$ anterior to and $16 \mathrm{~cm}$ above the subject's head. The speaker provided an auditory CS, which was a $600-\mathrm{msec}, 89-\mathrm{dB}$ (SPL), 1000-Hz pure tone superimposed on an ambient noise level of $82 \mathrm{~dB}$ provided by an exhaust fan. An $8-\mathrm{W}$ neon light tube was mounted $4 \mathrm{~cm}$ above the speaker. The US was a 100-msec, 3-mA, $50-\mathrm{Hz}$ ac electrical current delivered via stainless steel Autoclip wound clips positioned $10 \mathrm{~mm}$ apart and $15 \mathrm{~mm}$ posterior to the lateral canthus of the right eye. The stimulus events and response recording were controlled by an Apple II computer equipped with interfaces and software developed by Scandrett and Gormezano (1980).

To transduce movements of the NM, a small hook was attached to a silk loop sutured into the NM of the rabbit's right eye. The hook was connected to one end of an L-shaped crank. Inside a lightproof cylinder, movement of the crank rotated a disk of polarized filter, which was interposed between a light-emitting diode and a phototransistor covered by a fixed polarized filter. Thus, rotation of the disk produced changes in the intensity of light reaching the phototransistor through the fixed filter (see Gormezano \& Gibbs, 1988). The signal from the phototransistor was amplified and transmitted to an analogto-digital converter (10-msec sample rate) mounted in the computer.

\section{Drug}

The MK-801 [(+)-5-methyl-10,11-5H-dibenzo[a,d]cyclohepten5,10-imine maleate; Research Biochemicals, Inc.] was diluted with isotonic saline $(0.9 \% \mathrm{w} / \mathrm{v})$ and administered at a dose of 0.05 or $0.10 \mathrm{mg} / \mathrm{kg}$ i.v. at a concentration of $0.1 \mathrm{mg} / \mathrm{ml}$.

\section{Procedure}

Preliminary training. All rabbits received 1 day of preparation, 2 days of recovery, 1 day of adaptation, and 19 days of CS-US training. On the preparation day, hair surrounding the rabbit's right eye was removed, the eye was anesthetized with proxymetacaine hydrochloride (Opthaine), and a small loop of surgical silk (000 Dynex) was sutured into the NM. On the adaptation day, the animals were placed in the conditioning apparatus for $60 \mathrm{~min}$, but no substances were in- jected, nor were any stimuli presented. Following adaptation, the rabbits received training with the tone $\mathrm{CS}$. Each day contained 48 CS-US trials and 16 CS-alone trials. As part of another experiment, the CS-US interval was varied in a counterbalanced fashion over values of 200,400 , and $600 \mathrm{msec}$ (onset to onset). Following the end of the other experiment, all subjects received 2 more days of training with the 400-msec CS-US interval and also received i.v. injections of saline in a marginal ear vein $15-20 \mathrm{~min}$ before each session. These 2 days were designated as Days 1 and 2 of this experiment.

Extinction procedure. After preliminary training, the rabbits were randomly assigned to one of three drug conditions designated as Groups SAL $(n=4)$, MK.05 $(n=5)$, and MK.10 $(n=5)$. Group SAL received no MK-801 but did receive $0.10 \mathrm{ml}$ of isotonic saline before each session. Group MK.05 was injected with MK-801 (0.05 mg/kg i.v.). Group MK. 10 was injected with MK-801 (0.10 mg/kg i.v.). All injections were 15-20 min before each session. During Days 3-7, all groups received extinction training, in which each session contained $60 \mathrm{CS}$-alone presentations separated by a mean intertrial interval of $60 \mathrm{sec}$ (range $=50-70 \mathrm{sec}$ ). On Day 8 , all subjects received a saline injection, but extinction training was continued.

Reacquisition. On Days 9-11, CS-US training was reinstated. Each session contained $60 \mathrm{CS}-\mathrm{US}$ trials. In addition, there was a presentation of the US alone following each block of $10 \mathrm{CS}-\mathrm{US}$ trials. All subjects received a saline injection on Days 9 and 11. However, on Day 10, the subjects received their designated dosage of saline or MK-801 (namely, 0.05 or $0.10 \mathrm{mg} / \mathrm{kg}$ ).

\section{Response Definition}

A CR was defined as any extension of the NM exceeding $0.5 \mathrm{~mm}$ initiated during $400 \mathrm{msec}$ of the CS prior to the US (MarshallGoodell, Schreurs, \& Gormezano, 1982). For CS-alone trials, the same $400-\mathrm{msec}$ interval was used to score CRs.

\section{Results}

\section{CR Extinction: Initial Drug Effects}

Figure 1 shows the mean percentage of CRs on the last day of preliminary CS-US training (Day 2) and the first day of the CS-alone extinction procedure (Day 3). The mean for CS-US training represents the performance for the entire session, whereas the means for the first day of ex-

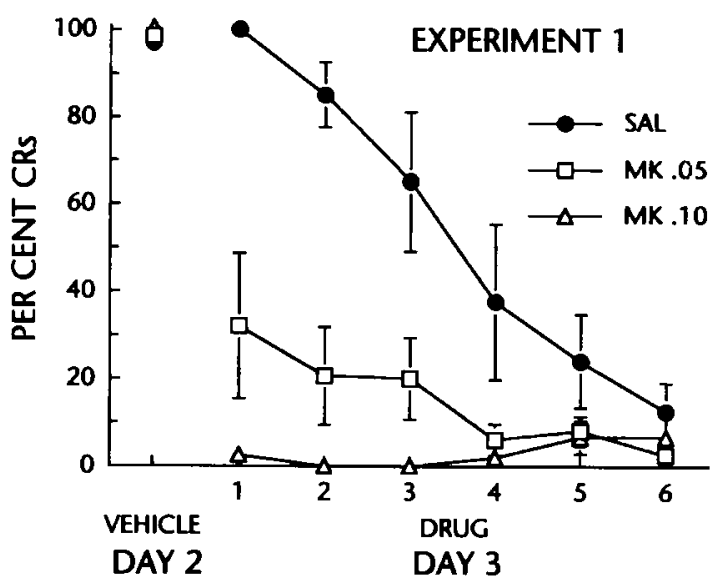

Figure 1. The mean percentage of CRs for Groups SAL, MK.05, and MK.10 on the final day of CS-US training and during subsequent CS-alone extinction training in Experiment 1. The figure shows the mean percentage CRs for Day 2 (vehicle) and six blocks of 10 trials on Day 3 (drug). 
tinction are plotted in six successive blocks. There were 10 CS-alone presentations in each block.

Inspection of Figure 1 reveals that, at the end of preliminary training, all groups were responding at a mean level of $98 \%$ CRs or greater. No subject responded to the CS at less than $94 \%$ CRs. On Day 3, all groups showed a decline in responding, which, however, was dose-dependent. Specifically, responding in Group SAL diminished steadily from $100 \%$ CRs to a mean of $12 \%$ CRs by the last block of the session. In contrast, responding in both groups that received MK-801 showed an abrupt drop in the first block of the extinction session. Group MK.05 dropped immediately to a mean level of $32 \%$ CRs and then diminished to $3 \%$ CRs. Only 1 rabbit showed more than $50 \% \mathrm{CRs}$ in the session. Finally, Group MK. 10 showed little responding at any point in the session, never more than $7 \%$ CRs. Only 1 rabbit in this group showed any responding, and that was never more than $33 \% \mathrm{CRs}$ in any single block. A statistical analysis confirmed that there was a downward, linear trend across the group means as a function of dose level $[F(1,11)$ $=27.04, p<.01]$. For Groups SAL, MK.05, and MK.10, the mean percentage CRs for Day 3 were $54 \%(S E=10 \%)$, $15 \%(S E=8 \%)$, and $3 \%(S E=2 \%)$, respectively.

\section{CR Extinction: Effects of Drug Removal}

Figure 2 shows the mean percentage of CRs on Days 7 and 8 . Day 7 was the last day on which the animals received their respective drug doses. On Day 8 , the CS-alone extinction procedure was continued, but all animals received only a saline injection. The means for both days are plotted in six successive blocks, each containing $10 \mathrm{CS}$ alone presentations.

As can be seen in Figure 2, all three groups showed negligible responding throughout Day 7's extinction procedure. Any apparent differences between the groups were

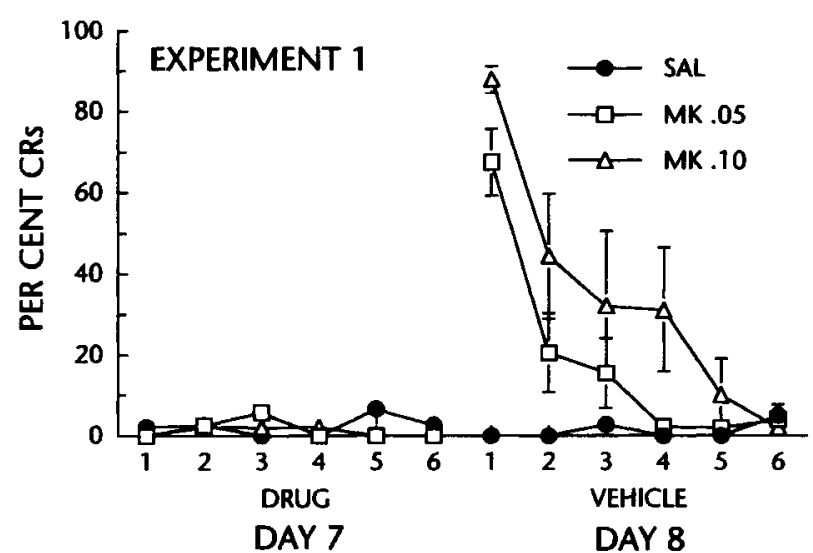

Figure 2. The effects of drug removal on Day 8. The figure shows the mean percentage of CRs over six blocks of 10 trials on each of Days 7 and 8 for Groups SAL, MK.05, and MK.10 in Experiment 1. On Day 7, Groups MK.05 and MK.10 received an injection of $M K-801$ prior to CS-alone training. On Day 8, all groups received an injection of the saline vehicle prior to $\mathrm{CS}$ alone training. small and not statistically significant (all $p s>.05$ ). On Day 8, Group SAL's responding remained at negligible levels. However, Groups MK.05 and MK.10 showed a massive, initial recovery in responding when their drug dosages were discontinued. Specifically, all animals in Group MK.05 showed an initial level of responding of $50 \%$ CRs or greater. In Group MK.10, the recovery was even more pronounced; all animals showed an initial level of $80 \%$ CRs or greater. During the course of Day 8, CRs in both groups were extinguished to a negligible level by the end of the day. For Groups SAL, MK.05, and MK.10, the overall means for Day 8 were $1 \%(S E=1 \%), 19 \%(S E=$ $6 \%)$, and $35 \%(S E=11 \%)$, respectively. There was a significant linear trend across the group means as a function of dose level $[F(1,11)=10.88, p<.01]$.

\section{Reacquisition: Effects of Drug Reinstatement}

Figure 3 shows the mean percentage of CRs on Days 9, 10 , and 11. For each day, the means are plotted in six blocks, each containing $10 \mathrm{CS}-$ US trials. On Day 9, in which all subjects received CS-US training and a saline injection, $\mathrm{CR}$ reacquisition was very rapid; all animals achieved at least $80 \%$ CRs during the session.

On Day 10, reintroduction of the drug dosage caused an initial drop in responding in Group MK.10 to a mean of $38 \%$ CRs in the first block of CS-US trials. Among individual subjects, 4 out of the 5 rabbits showed a drop in responding to $40 \%$ CRs or less in the first block of trials. Thereafter, responding recovered steadily to a mean level of $75 \%$ CRs in the last block of trials. For Group MK.05, reintroduction of the drug dosage caused a drop in responding to an initial mean of $77 \%$ CRs; all subjects showed a drop to $80 \%$ CRs or less. Responding on subsequent trial blocks hovered around a mean of $78 \%$ CRs. In Group SAL, responding throughout Day 10 remained at a high level, hovering around 93\% CRs. In the initial block of CS-US trials, all 4 animals showed $90 \%$ CRs or greater. Statistical comparisons confirmed that there were significant differences between the groups in the pattern of their performance during Day 10 [dose (linear) $\times$ blocks (linear), $F(1,11)=$ $5.13, p<.05]$.

On Day 11, in which no MK-801 was administered, responding in all groups was at a mean level of $95 \%$ CRs or greater in the first block of trials. No individual subject showed less than $80 \%$ CRs in the first block. In subsequent trial blocks, all three groups showed a mean level of $93 \%$ CRs. The one exception was a single subject in Group SAL that temporarily ceased responding in the middle of the session.

\section{UR Magnitude}

To ascertain whether MK- 801 produced any motor deficits in the performance of the NM response, we examined the magnitude of the UR on the US-alone trials given on Days 9-11. In Groups MK.05 and MK.10, the injection of MK-801 on Day 10 yielded only a small reduction in the UR magnitude, which was not statistically significant $(F<1)$. Averaging across Groups MK.05 and MK. 10, the 


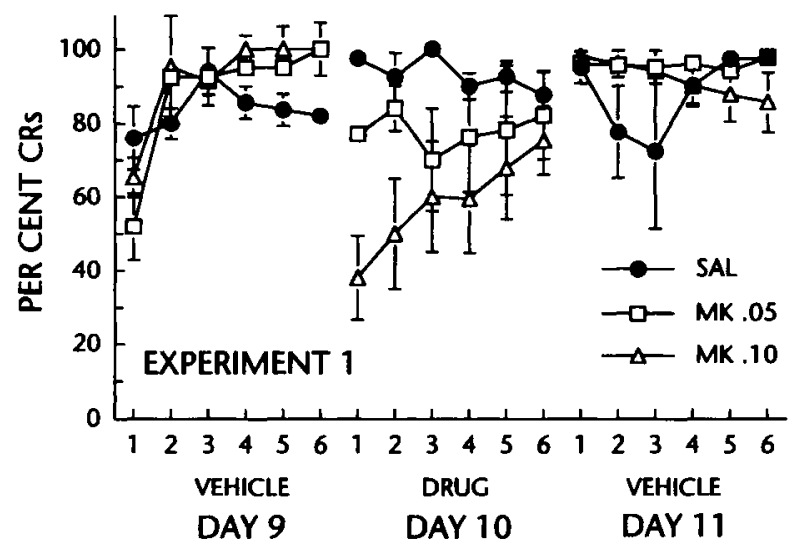

Figure 3. The effects of drug reinstatement during reacquisition training on Days 9-11. The figure shows the mean percentage CRs for six blocks of 10 trials on each of Days 9,10 , and 11 for Groups SAL, MK.05, and MK.10 in Experiment 1. On Days 9 and 11, all groups received an injection of the saline vehicle prior to CS-US training. On Day 10, Groups MK.05 and MK.10 received an injection of $\mathrm{MK}-\mathbf{8 0 1}$ prior to CS-US training.

mean UR magnitude for Day 10 was $5.8 \mathrm{~mm}(S E=0.6)$, relative to $6.5 \mathrm{~mm}(S E=0.8)$ and $6.4 \mathrm{~mm}(S E=0.6)$ on Days 9 and 11 , respectively.

\section{Discussion}

Experiment 1 demonstrated clearly that administration of MK-801 during CS-alone presentations protected the $\mathrm{CR}$ from extinction. The larger dose $(0.10 \mathrm{mg} / \mathrm{kg})$ produced greater protection than did the smaller dose $(0.05 \mathrm{mg} / \mathrm{kg})$. In addition to demonstrating protection from extinction, Experiment 1 also confirmed that MK- 801 produces an immediate, profound suppression of CR performance. This suppressive effect was seen clearly in both drug groups on Day 3, which was the first day of extinction. Throughout the 5 days of extinction, Group MK.10 showed virtually no CRs. The suppressive effect of MK-801 was seen to a lesser extent on Day 10, which was the second day of CS-US reacquisition training. On that day, responding initially showed a substantial decline but thereafter largely recovered. Finally, examination of the UR failed to reveal any gross sensory or motor deficits in NM system.

The present findings support the hypothesis that MK801 disrupts CS processing in a relatively specific manner. The protection from extinction afforded by MK-801 is, of course, the new finding. Moreover, consistent with previous findings by Cox et al. (1994), the suppression of CRs contrasts strongly with lack of effect on the UR. The only exception to this pattern was the observation that CRs during CS-US training on Day 10 recovered while under the influence of MK-801. This recovery might reflect the development of tolerance to the drug after 5 days of administration during extinction. However, Cox et al. (1994) saw no evidence of tolerance over 9 days of CS-US training conducted under the drug. Rather than reflecting drug tolerance, the recovery may reflect an enrichment of CS pro- cessing - - enhanced attention - that arose from the previous schedule of acquisition, extinction, and reacquisition (Lubow \& Weiner, 1981; Mackintosh, 1975, 1977; Schmajuk \& Moore, 1988). In this latter circumstance, the drug could well have had less impact on CS processing.

\section{EXPERIMENT 2}

In some respects, Experiment 2 was two experiments in one. First, Experiment 2 was conducted to confirm that MK-801 protected CRs from extinction. Second, Experiment 2 was conducted to replicate previous findings by Cox et al. (1994) that MK-801 hinders CR acquisition during CS-US pairings. Extinction and acquisition were conducted concurrently for each subject by using a discrimination reversal procedure. That is, all subjects were first given discrimination training in which one CS (A) was paired with the US, and another CS (B) was presented alone. This training was conducted without any drug injections. After responding was established to CS A and not CS B, all subjects were transferred to discrimination reversal. That is, CS A was presented alone; therefore, its CRs were subject to extinction. Conversely, CS B was paired with the US, thus allowing for $\mathrm{CR}$ acquisition to CS B. During discrimination reversal, half the subjects received a $0.10-\mathrm{mg} / \mathrm{kg}$ i.v. dose of MK-801, and the other half of the subjects received a saline injection. On the last day of discrimination reversal, all subjects were tested without the drug.

\section{Method}

\section{Subjects}

In Experiment 2, the subjects were 16 naive female albino rabbits.

\section{Apparatus and Procedure}

Except where indicated, the apparatus and procedure were identical to those used in Experiment 1. A light CS was provided by flashing the houselight at $20 \mathrm{~Hz}$. Both the tone CS and the light CS were $250 \mathrm{msec}$ in duration. On CS-US trials, the interval between CS onset and US onset was $250 \mathrm{msec}$. All rabbits received 1 day of preparation, 2 days of recovery, 1 day of adaptation, and 14 days of training. The rabbits were randomly assigned to two groups $(n=8)$ designated as Groups MK.10 and SAL.

On Days 1-6, Groups MK. 10 and SAL received differential conditioning. Each session consisted of 30 trials in which one $\mathrm{CS}$ was paired with the US $(\mathrm{A}+)$. Intermixed among the $\mathrm{A}+$ trials, there were 30 trials in which the other $\mathrm{CS}$ was presented alone $(\mathrm{B}-)$. Trials were presented in blocks in which $10 \mathrm{~A}+$ and $10 \mathrm{~B}$ - trials were randomly interspersed. For half the subjects in each group, CS A was the tone, and CS B was the light. For the other half of the subjects, CS A was the light and CS B was the tone. On Days $1-5$, no injections were given, but, on Day 6, all subjects received an i.v. injection of saline.

On Days $7-14$, both groups received a discrimination reversal procedure. That is, Stimulus A was presented alone ( $\mathrm{A}-$ ), and Stimulus B was paired with the US $(B+)$. On Days 7-13, Group MK.10 received an i.v. injection of $0.10-\mathrm{mg} / \mathrm{kg}$ MK -801 , and Group SAL received an i.v. injection of saline $(0.1 \mathrm{ml}) 15-20 \mathrm{~min}$ before each session. On Day 14, both groups received a saline injection.

\section{Results}

Figure 4 shows the percentage of CRs over Days 1-14 of Experiment 2. The means for Group MK.10 are de- 
picted in the upper row of panels. The means for Group SAL are depicted in the lower row. In each row, the left panel shows the daily means for A+ and B - trials on Days $1-6$. The middle panel shows the daily means for $A-$ and $\mathrm{B}+$ trials on Days 7-13. The right panel shows the means for three 10-trial blocks of A- and B+ on Day 14.

\section{Initial Differential Conditioning}

Examination of the left panels of Figure 4 reveals that both groups showed acquisition of differential conditioning. Specifically, responding to A+ rose to levels greater than $90 \%$ CRs by Day 6 . In contrast, responding to $B-$ remained at less than $3 \%$ CRs on all days. Any apparent differences between the two groups were small and not significant (all $F_{\mathrm{S}}<1$ ).

\section{Discrimination Reversal: Drug Administration}

As can be seen in the middle panels of Figure 4, the introduction of MK-801 to Group MK.10 largely abolished responding to both $\mathrm{A}-$ and $\mathrm{B}+$ for the first 4 days of discrimination reversal. Specifically, on Days 7-10, the mean levels were less than $10 \%$ CRs. However, on Days 11, 12, and 13 , there were some rises in responding. On Day 13, the mean levels reached $12 \%$ and $23 \%$ CRs to $\mathrm{A}-$ and $\mathrm{B}+$, respectively. However, this rise was confined to only 2 of the 8 rabbits in the group. On Day 13,1 of those rabbits showed $100 \% \mathrm{CRs}$ to $\mathrm{B}+$ and $63 \% \mathrm{CRs}$ to $\mathrm{A}-$. The other rabbit showed $75 \% \mathrm{CRs}$ to $\mathrm{B}+$ and $7 \% \mathrm{CRs}$ to $\mathrm{A}-$. The remaining 6 rabbits showed less than $10 \%$ CRs to both stimuli. In statistical comparisons, the apparent rise in responding to either stimulus across days failed to reach significance $(p s>.10)$.

Group SAL showed successful discrimination reversal. That is, responding to A - extinguished across days to a mean level of $10 \%$ CRs by Day 13. Conversely, responding to $\mathrm{B}+$ rose steadily across days and attained a mean level of $75 \%$ CRs by Day 13 . Examination of the individual rabbits revealed that all 8 of them showed a reversal in responding to the two stimuli. Statistical comparisons confirmed that there was a significant decline in responding to $\mathrm{A}-[F(1,14)=23.93, p<.01]$ and a significant increase in responding to $\mathrm{B}+[F(1,14)=63.93, p<.01]$.

\section{Discrimination Reversal: Drug Suspension}

When administration of MK-801 was suspended on Day 14, Group MK.10 showed a massive recovery in responding to $\mathrm{A}-$. Specifically, responding recovered from $10 \%$ CRs on Day 13 to $79 \%$ CRs in the first block of Atrials. All rabbits but 1 reached a level of $70 \%$ CRs or greater. Subsequently, responding to $\mathrm{A}-$ declined to a mean of $60 \%$ CRs by the end of the session. In contrast, Group SAL showed negligible responding to $\mathrm{A}$ - throughout the session. Only 2 rabbits in Group SAL showed evidence of $\mathrm{CRs}$ to $\mathrm{A}-$. The 2 rabbits showed some spontaneous re-
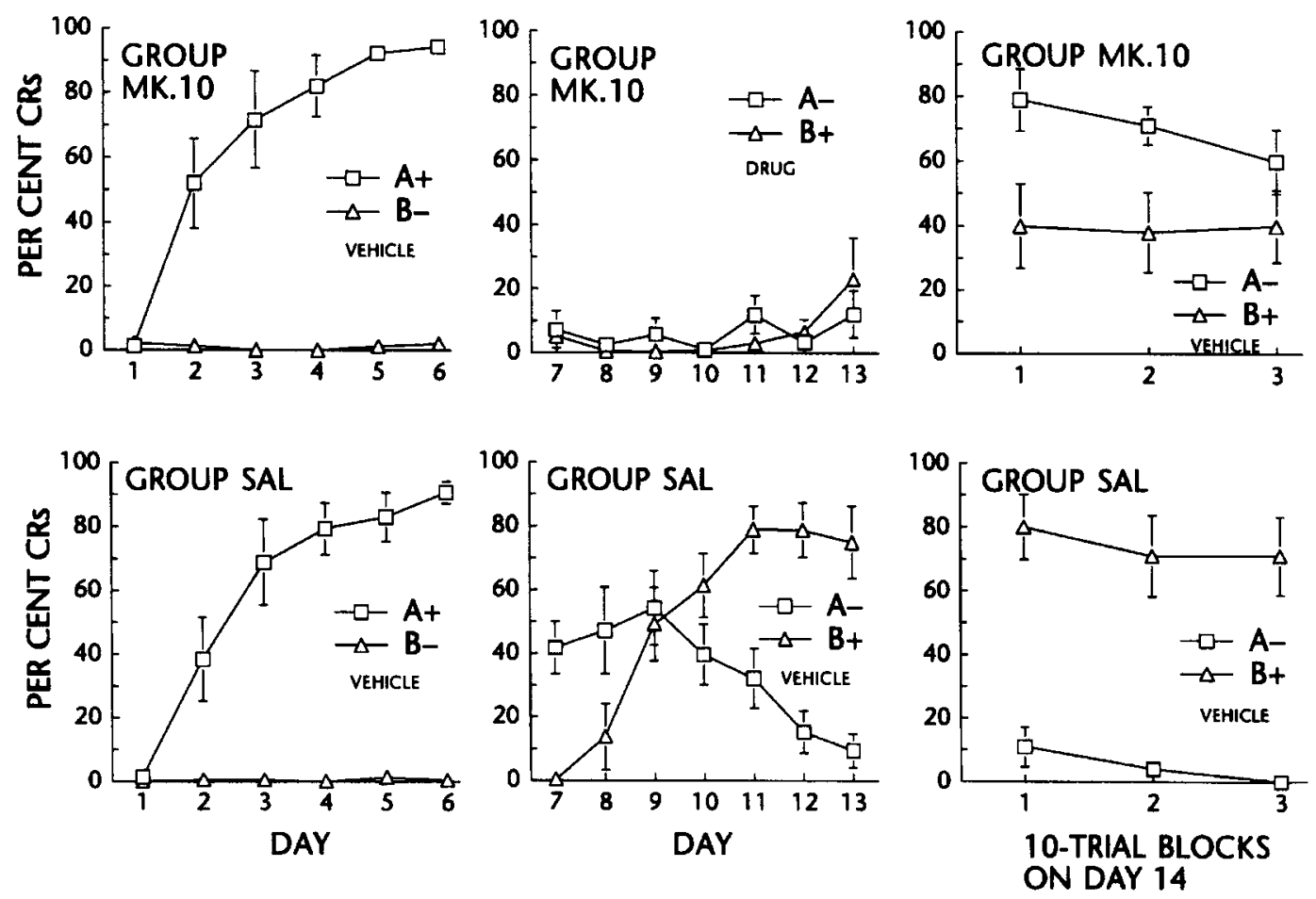

Figure 4. The effect of drug administration on discrimination reversal learning in Experiment 2. On Days 1-6 (left panels), both groups received differential conditioning $(A+$ vs. $B-$ ) with the saline vehicle. On Days $7-13$ (middle panels), both groups received reversal training (A - vs. B+), in which Group MK.10 received MK-801 before each session. On Day 14 (right panels), both groups continued to receive reversal training, but Group MK.10 received the saline vehicle before the training session. Throughout reversal training, Group SAL received saline before each session. 
covery on the first block of trials, at levels of $50 \%$ and $30 \%$ CRs, respectively. Statistical analyses confirmed that the mean level of responding to A - for Group MK.10 on Day $14(M=70 \% \mathrm{CRs})$ was significantly greater than the mean level of responding to A - for Group SAL ( $M=5 \%$ CRs) $[F(1,14)=82.51, p<.01]$.

With regard to B+ trials, Group MK.10's level of responding hovered around a mean of $39 \%$ CRs throughout the session. This level of responding appeared higher than that seen on Day 13, the last day of drug administration. This increase in responding reflected an even split in the 8 rabbits' performance. Four of the rabbits showed levels of responding greater than $50 \%$ CRs. These included the 2 subjects that had shown $\mathrm{CR}$ acquisition on $\mathrm{B}+$ trials during the previous days containing drug administration. The remaining 4 subjects showed little or no responding to $\mathrm{B}+$ during Day 14. In contrast to Group MK.10's moderate level of responding to $\mathrm{B}+$, Group SAL showed a consistently high level of responding, hovering around $74 \% \mathrm{CRs}$. One subject, however, failed to respond to B+ on Day 14. For unknown reasons, this same subject had shown a precipitous drop in responding on the previous day. All other subjects in Group SAL showed response levels greater than $90 \%$ CRs on B + trials. Statistical analyses were conducted to determine whether the mean level of responding for Group MK.10 on Day $14(M=39 \%$ CRs $)$ was significantly lower than the mean level of responding to $\mathrm{B}+$ for Group SAL ( $M=74 \% \mathrm{CRs})$. However, as a consequence of the large variance across subjects in Group MK.10, the apparent difference failed to reach the declared level of statistical significance $[F(1,14)=4.09, p<.10]$.

A comparison of the levels of differentiation between $A$ and B in the two groups confirmed that Group SAL had shown discrimination reversal. That is, responding to $\mathrm{A}-$ was significantly less than responding to $\mathrm{B}+[F(1,14)=$ $27.94, p<.01$ ]. In contrast, Group MK.10 failed to show discrimination reversal. That is, responding to $\mathrm{A}-$ was significantly greater than responding to $\mathrm{B}+[F(1,14)=5.52$, $p<.05]$.

\section{Discussion}

Experiment 2 confirmed and extended previous findings. Specifically, MK- 801 both protected CRs from extinction and suppressed CR acquisition. These effects were obtained within subjects on a concurrent basis. Moreover, they were obtained after previous differential conditioning. Thus, a previous history of reinforcement and nonreinforcement for A and B, respectively, did not appear to diminish the effect of MK-801 on subsequent extinction and acquisition using the same stimuli.

\section{GENERAL DISCUSSION}

Much of the interest surrounding MK-801 is that it may impair the synaptic plasticity that underlies associative learning. However, the most parsimonious interpretation of the present results is that MK-801 disrupted sensory processing of the CS. Specifically, as a consequence of MK-801 administration, the CR was entirely intact after extensive exposure to CS-alone presentations. Moreover, MK-801 suppressed CR performance during both CSalone and CS-US trials.

The present results are consistent with previous findings that MK-801 disrupts CS processing in the NM preparation. Moreover, the apparent effects of MK-801 on CS processing are consistent with findings that other drugs also affect sensory processing of the CS. For example, haloperidol (Harvey \& Gormezano, 1981), morphine (Schindler, Gormezano, \& Harvey, 1984), and scopolamine (Harvey, Gormezano, \& Cool-Hauser, 1983) all retarded CR acquisition and suppressed the expression of established CRs. Conversely, D-lysergic acid diethylamide (LSD) increased the rate of CR acquisition and enhanced the expression of established CRs (Gormezano \& Harvey, 1980).

Despite the evidence that MK-801 disrupts CS processing in the NM response, the exception to this pattern of results is the report by Robinson et al. (1993) that administration of MK-801 during CS-alone exposures failed to affect latent inhibition. That is, $\mathrm{CR}$ acquisition during later CS-US pairings was retarded, irrespective of whether MK-801 had been administered during the CS-alone exposures. Moore (personal communication, June 6, 1995) has suggested that, because NMDA receptors may be sites for the Hebbian convergence of two neural signals, there is no reason to suppose that CS preexposure engages these receptors. By contrast, $\mathrm{CR}$ acquisition and $\mathrm{CR}$ extinction involve the convergence of two neural signals. According to contemporary theories of conditioning, these two signals are (1) the CS input and (2) a "reinforcement signal" arising from the discrepancy between the "expected" and actual US inputs (Rosenfield \& Moore, 1995; Sutton \& Barto, 1990). During acquisition, this signal has a positive value, and, during extinction, the signal has a negative value. In the case of latent inhibition, contemporary theories of conditioning contend that a different learning process is responsible. This process is usually depicted as a habituationlike decrease in attention to the CS or, more generally, a decrease in its ability to enter associations (Solomon, 1987). ${ }^{1}$ Apart from possible differences in synaptic mechanisms, latent inhibition relies on pathways through the hippocampus (Solomon, 1987), whereas CR extinction as well as CR acquisition rely on cerebellar pathways (Perrett \& Mauk, 1995; Thompson, 1986). In conclusion, the neural substrates of latent inhibition appear distinct from those of CR extinction and thus may be insensitive to the effects of MK-801 on CS processing. On a more positive note, the discrepancy in sensitivity of latent inhibition and CR extinction to MK-801 suggests that the neuroanatomical locus of MK-801's effects on CS processing may lie just upstream from the synapses that underpin CR acquisition and expression in the NM preparation.

Although disruption of CS processing is the most parsimonious explanation of the present data, there are at least two alternative explanations. Both assume that MK801 has separate effects on learning and expression. The first, dual-effect hypothesis assumes that MK-801 acts at two points in the pathways that mediate $C R$ acquisition in the NM preparation. Specifically, MK-801 blocks learn- 
ing at the point of CS-US convergence and blocks expression by disrupting the CR output pathway (see Miserendino \& Davis, 1993). Under this hypothesis, both the deleterious effect on CR acquisition and protection from extinction would be attributed to MK-801's disruption of learning. Concomitantly, the immediate decline in CR performance caused by MK- 801 would be attributed to its disruption of the CR output pathway. At a purely behavioral level, it would be difficult to distinguish this dual-effect hypothesis from the CS-processing hypothesis. However, given that the essential pathways for NM conditioning have been identified, recordings of activity in the different segments of the pathways after MK-801 administration might provide the answer.

The second, dual-effect hypothesis assumes again that MK-801 directly blocks the formation of associations. In addition, it assumes state-dependent learning (Denny, 1994; Overton, 1964). According to this hypothesis, the immediate decline in responding caused by MK- 801 reflects a massive generalization decrement caused by a change in the internal stimulus context produced by the drug. During extinction training, both effects would operate to protect the CR from extinction. That is, in addition to any interference with the associative process caused by MK-801, the context induced by MK-801 may have prevented extinction of the CR to the CS trained in the nondrug context. Conversely, recovery of responding when MK-801 was suspended would arise from reinstatement of the nondrug context.

This second hypothesis relies heavily on the assumption that the context induced by MK- 801 is almost completely distinct from the nondrug state. Although context effects have been obtained in the rabbit NM preparation using external stimuli (Hinson, 1982; Macrae \& Kehoe, 1995), none of these effects have been as large as those required to justify such a heavy reliance on drug versus nondrug contextual differences. Moreover, in the rabbit NM preparation, extinction of the CR does not appear to depend on the internal context produced by the presence versus the absence of the US (Napier, Macrae, \& Kehoe, 1992). Conceivably, drug context effects could be larger than those induced by external stimuli. However, the differences in the internal context would have to completely override the CS and the external context.

\section{REFERENCES}

Cegavske, C. F., Harrison, T. A., \& Torigoe, Y. (1987). Identification of the substrates of the unconditioned response in the classically conditioned, rabbit, nictitating-membrane preparation. In I. Gormezano, W. F. Prokasy, \& R. F. Thompson (Eds.), Classical conditioning (pp. 65-91). Hillsdale, NJ: Erlbaum.

Chapman, P. F., Steinmetz, J. E., \& Thompson, R. F. (1988). Classical conditioning does not occur when direct stimulation of the red nucleus or cerebellar nuclei is the unconditioned stimulus. Brain Research, 442, 97-104.

Coleman, S. R., \& Gormezano, I. (1971). Classical conditioning of the rabbit's (Oryctolagus cuniculus) nictitating membrane response under symmetrical CS-US interval shifts. Journal of Comparative \& Physiological Psychology, 77, 447-455.

Collingridge, G. L., KeHL, S. J., \& MCLenNan, H. (1983). Excitatory amino acids in synaptic transmission in the Schaffer collateral- commissural pathway of the rat hippocampus. Journal of Physiology, 334, 33-46.

Cotman, C. W., \& Iversen, L. L. (1987). Excitatory amino acids in the brain-Focus on NMDA receptors. Trends in Neurosciences, 10, 263-265.

CoX, J., Guthrie, R., Macrae, M., \& Kehoe, E. J. (1994). MK801 impairs acquisition and expression of conditioned responses in the rabbit nictitating membrane preparation. Psychobiology, 22, 156-166.

Cox, J., \& WestвRook, R. F. (1994). The NMDA receptor anatagonist MK-801 blocks acquisition and extinction of conditioned hypoalgesic responses in the rat. Quarterly Journal of Experimental Psychology, 47B, 187-210.

DENNY, M. R. (1994). State-dependent learning. In R. J. Corsini (Ed.), Encylopedia of psychology (p. 464). New York: Wiley.

Falls, W. A., Miserendino, M. J. D., \& Davis, M. (1992). Extinction of fear-potentiated startle: Blockade by infusion of an NMDA anatagonist into the amygdala. Journal of Neuroscience, 12, 854-863.

GilberT, M. E., \& MACK, C. M. (1990). The NMDA antagonist MK-801 suppresses long-term potentiation, kindling and kindling-induced potentiation in the perforant path of the unanesthetized rat. Brain Research, 519, 89-96.

Gluck, M. A., \& Myers, C. E. (1995). Representation and association in memory: A neurocomputational view of hippocampal function. Current Directions in Psychological Science, 4, 23-29.

Gormezano, I. (1966). Classical conditioning. In J. B. Sidowski (Ed.), Experimental methods and instrumentation in psychology (pp. 385420). New York: McGraw-Hill.

Gormezano, I., \& GibBs, C. M. (1988). Transduction of the rabbit's nictitating membrane response. Behavior Research Methods, Instruments, \& Computers, 20, 18-21

Gormezano, I., \& Harvey, J. A. (1980). Sensory and associative effects of LSD in classical conditioning of rabbit (Oryctolagus cuniculus) nictitating membrane response. Journal of Comparative \& Physiological Psychology, 94, 641-649.

GRANT, N. (1994). Transfer between CSs differing in CS-US interval and/or modality in the rabbit nictitating membrane preparation: Test of a real-time model. Honours thesis, University of New South Wales, Sydney, Australia.

HaRvey, J. A., \& Gormezano, I. (1981). Effects of haloperidol and pimozide on classical conditioning of the rabbit nictitating membrane response. Journal of Pharmacology \& Experimental Therapy, 221, 289-294.

Harvey, J. A., Gormezano, I., \& CoOl-Hauser, V. A. (1983). Effects of scopolamine and methylscopolamine on classical conditioning of the rabbit nictitating membrane response. Society for Neuroscience Abstracts, 9, 330 .

Hinson, R. E. (1982). Effects of UCS preexposure on excitatory and inhibitory rabbit eyelid conditioning: An associative effects of conditioned contextual stimuli. Journal of Experimental Psychology: Animal Behavior Processes, 8, 49-61.

HiтchCOCK, J. M., \& DAVIS, M. (1986). Lesions of the amygdala, but not the cerebellum or red nucleus, block conditioned fear as measured by the potentiated startle paradigm. Behavioral Neuroscience, 100, 11-22.

KeITH, J. R., \& RuDY, J. W. (1990). Why NMDA-receptcr-dependent long-term potentiation may not be a mechanism of learning and memory: Reappraisal of the NMDA-receptor blockade strategy. Psychobiology, 18, 251-257.

Kemp, J. A., Foster, A. C., \& Wong, E. H. F. (1987). Non-competitive antagonists of excitatory amino acid receptors. Trends in Neuro. sciences, 10, 294-298.

Kıм, M., Campeau, S., Falls, W. A., \& Davis, M. (1993). Infusion of the non-NMDA receptor antagonist $\mathrm{CNQX}$ into the amygdala blocks the expression of fear-potentiated startle. Behavioral \& Neural Biology, 59, 5-8.

Lubow, R. E., \& WeINER, I. (1981). Conditioned attention theory. In G. H. Bower (Ed.), The psychology of learning and motivation (Vol. 15, pp. 1-49). San Diego, CA: Academic Press.

Lynch, M. A., Errington, M. L., Clements, M. P., Bliss, T. V. P., Redini-Del Negro, C., \& Laroche, S. (1990). Increases in glutamate release and phosphoinositide metabolism associated with longterm potentiation and classical conditioning. Progress in Brain Research, 83, 251-256. 
Mackintosh, N. J. (1975). A theory of attention: Variation in the associability of stimuli with reinforcement. Psychological Review, 82, 276-298.

Mackintosh, N. J. (1977). Stimulus control: Attentional factors. In W. K. Honig \& J. E. R. Staddon (Eds.), Handbook of operant behavior (pp. 481-513). Englewood Cliffs, NJ: Prentice-Hall.

MACRAE, M., \& KeHOE, E. J. (1995). Transfer between conditional and discrete discriminations in conditioning of the rabbit nictitating membrane response. Learning \& Motivation, 26, 380-402.

Marshall-Goodell, B., Schreurs, B. G., \& Gormezano, I. (1982). Ruler vs. the Apple II/FIRST system analysis of analog signals in classical conditioning. Behavior Research Methods \& Instrumentation, 14, 519-525.

Miserendino, M. J., \& Davis, M. (1993). NMDA and non-NMDA antagonists infused into the nucleus reticularis pontis caudalis depress the acoustic startle reflex. Brain Research, 623, 215-222.

Miserendino, M. J. D., Sananes, C. B., Melia, K. R., \& Davis, M. (1990). Blocking of acquisition but not expression of conditioned fear-potentiated startle by NMDA anatagonists in the amygdala. $\mathrm{Na}$ ture, 345, 716-718.

Morris, R. G. M., Davis, S., \& Butcher, S. P. (1990). Hippocampal synaptic plasticity and $N$-methyl-D-aspartate receptors: A role in information storage. Philosophical Transactions of the Royal Society of London: Series B, 329, 187-204.

Muller, D., Joly, M., \& LyNCH, G. (1988, December 23). Contributions of quisqualate and NMDA receptors to the induction and expression of LTP. Science, 242, 1694-1697.

NAPIER, R. M., MACRAE, M., \& KeHOE, E. J. (1992). Rapid reacquisition in conditioning of the rabbit's nictitating membrane response. Journal of Experimental Psychology: Animal Behavior Processes, 18, 182-192.

OVERTON, D. A. (1964). State dependent or "dissociated" learning produced with pentobarbital. Journal of Comparative \& Physiological Psychology, 57, 3-12.

Pearce, J. M., \& Hall, G. (1980). A model for Pavlovian learning: Variations in the effectiveness of conditioned but not of unconditioned stimuli. Psychological Review, 87, 532-552.

Perretr, S. P., \& Mauk, M. D. (1995). Extinction of conditioned eyelid responses requires the anterior lobe of the cerebellar cortex. Journal of Neuroscience, 15(3, Pt. 1), 2074-2080.

RoBINSON, G. B. (1993). MK801 retards acquisition of a classically conditioned response without affecting conditioning-related alterations in perforant path-granule cell synaptic transmission. Psychobiology, 21, 253-264.
Robinson, G. B., Port, R. L., \& Stillwell, E. (1993). Latent inhibition of the classically conditioned rabbit nictitating membrane response is unaffected by the NMDA antagonist MK801. Psychobiology, 21, 120124.

Rosenfield, M. E., Davydaitis, A., \& Moore, J. W. (1985). Brachium conjunctivum and rubrobulbar tract: Brainstem projections of red nucleus essential for the conditioned nictitating membrane response. Physiology \& Behavior, 34, 751-759.

Rosenfield, M. E., \& MoORE, J. W. (1995). Connections in cerebellar cortex (Larsell's HVI) in the rabbit: A WGA-HRP study with implications for classical eyeblink conditioning. Behavioral Neuroscience, 109, 1106-1118.

SCANDRETT, J., \& GoRmEZANO, I. (1980). Microprocessor control and A/D data acquisition in classical conditioning. Behavior Research Methods \& Instrumentation, 12, 120-125.

Schindler, C. W., Gormezano, I., \& Harvey, J. A. (1984). Sensory and associative effects of morphine and naloxone in classical conditioning of the rabbit nictitating membrane response. Psychopharmacology, 83, 114-121

Schmajuk, N. A., \& Moore, J. W. (1988). The hippocampus and the classically conditioned nictitating membrane response: A real-time attentional-associative model. Psychobiology, 16, 20-35.

Solomon, P. R. (1987). Neural and behavioral mechanism involved in learning to ignore irrelevant stimuli. In I. Gormezano,W. F. Prokasy, \& R. F. Thompson (Eds.), Classical conditioning (pp. 117-159). Hillsdale, NJ: Erlbaum.

Sutton, R. S., \& Barto, A. G. (1990). Time-derivative models of Pavlovian reinforcement. In M. Gabriel \& J. W. Moore (Eds.), Learning and computational neumscience (pp. 497-537). Cambridge, MA: MIT Press

Thompson, R. F. (1986, August 29). The neurobiology of learning and memory. Science, 233, 941-947.

THOMPSON, R. F. (1990). Neural mechanisms of classical conditioning in mammals. Philosophical Transactions of the Royal Society of London: Series B, 329, 161-170.

\section{NOTE}

1. Although latent inhibition is a nonassociative phenomenon in operational terms, there have been repeated attempts to explain latent inhibition by applying associative principles to changes in attentional/associability processes (e.g., Gluck \& Myers, 1995; Lubow \& Weiner, 1981; Pearce \& Hall, 1980; Schmajuk \& Moore, 1988). 